\title{
Quality, trade, and growth
}

\author{
C. Simon Fan* \\ Department of Economics, Lingnan University, Tuen Mun, Hong Kong \\ Received 16 May 2003; accepted 15 September 2003 \\ Available online 5 August 2004
}

\begin{abstract}
This paper analyzes the roles of product quality and increasing returns in international division of labor and economic development. Because the qualities of different intermediate goods are highly complementary in producing the quality of the final good, a poor economy will choose to be in autarky if its average level of human capital is sufficiently low. Thus, the heterogeneity of human capital may hamper the division of labor. Further, by linking quality, trade and growth, this model simultaneously explains the East Asian Miracle and the empirical finding of conditional convergence.

(C) 2004 Elsevier B.V. All rights reserved.
\end{abstract}

Keywords: Quality; Heterogeneity of human capital; Extent of the market; Growth

\section{Introduction}

In his classical book that established the foundation of modern economics, the wealth of nations, Smith (1776) assigned a prominent role to increasing returns and the division of labor in his explanation for economic development. In particular, one of Smith's central theorems is that the degree of specialization is limited by the extent of market. For the past few decades, almost two centuries after Smith's seminal work, the studies of increasing returns and the division of labor seem to have experienced a renaissance and significant contributions have been made in this area of research. ${ }^{1}$

* Tel.: +852 2616 7206; fax: +852 28917940 .

E-mail address: fansimon@ln.edu.hk (C.S. Fan).

1 A very partial list of some recent important contributions includes [Krugman (1979); Ethier (1982); Romer (1987); Grossman and Helpman (1991); Yang and Borland (1991); Becker and Murphy (1992); Yang and Ng (1993); Kelly (1997)].

0167-2681/\$ - see front matter @ 2004 Elsevier B.V. All rights reserved. doi:10.1016/j.jebo.2003.09.011 
This paper attempts to extend the existing literature by examining the roles of product quality and increasing returns in international trade and economic development. It starts with the notion that in the modern production of specialization, the qualities of different intermediate goods are highly complementary in producing the quality of the final good. ${ }^{2}$ It also notes that the demand for quality increases with income, so there is a conflict in the preferences for the ideal quality of consumption between rich and poor countries. Then, it shows that despite the higher efficiency of international specialization in the production of the goods of any given quality, a poor country may choose an "inferior" autarkic production technology to produce more quantity rather than engage in international trade and produce some intermediate goods of the high quality of international standard. Thus, the heterogeneity of human capital may hamper the division of labor. ${ }^{3}$ In the international context, trade in manufactured goods does not occur between countries with very different levels of per capita human capital or income.

The analysis yields some interesting policy implications. For example, if rich economies transfer some resources to poor economies to help them develop their educational infrastructure, individuals in poor economies will accumulate more human capital so that the poor economies may switch their production from autarky to international specialization. Consequently, there will be a higher degree of the division of labor, enhancing the productivity of the global economy. Thus, the transfer of some resources from rich to poor countries can lead to an outcome of Pareto improvement for all countries.

This model also examines the dynamic effects of trade, shedding light on the patterns of cross-country growth. The close relationship between international trade and economic growth has long been recognized. ${ }^{4}$ In particular, in an influential contribution, Lucas (1993) argues that if we want to understand economic growth better, we should have models that can explain the East Asian Miracle. ${ }^{5}$ Lucas suggests that the East Asian Miracle has two major implications. First, it exemplifies trade-induced rapid growth performances. Second, it implies that middle income countries tend to grow fastest. More recently, Ventura points out that a more satisfactory model on trade and growth should be able to explain both the East Asian Miracle and the empirical finding of conditional convergence that for the economies that have similar underlying structures, poor economies tend to catch up with rich ones (e.g. Mankiw et al., 1992; Barro and Sala-i-Martin, 1995).

By linking quality, trade and growth, this paper develops a model that complements Ventura and other existing literature in explaining both the East Asian Miracle and the conditional convergence finding. Firstly, the model implies that a poor economy with very low average level of human capital will choose to produce low-quality manufactured goods

\footnotetext{
${ }^{2}$ Kremer (1993) makes a similar assumption and conducts a comprehensive survey of much empirical evidence in support of it.

3 Becker and Murphy (1992) also note that the extent of market is not the only constraint in specialization. In fact, they argue that other factors, such as "coordination cost" in their model, have far more significant influence on the division of labor.

${ }^{4}$ For some recent important theoretical literature that links trade with growth, see [Grossman and Helpman (1991); Young (1991); Matsuyama (1992); Copeland and Kotwal (1997); Ventura (1997); Sachs et al. (2002); Galor and Mountford (2003)].

5 The East Asian Miracle refers to the phenomenon that for several decades, a group of small export-oriented East Asian economies had grown at remarkably high rates.
} 
in autarky, so it will have relatively low growth rate. Meanwhile, under some reasonable conditions, the poor economy will gradually develop through human capital accumulation, and its average level of human capital will ultimately reach the threshold level of participating in international industrial specialization. When the threshold level is reached, the economy will experience a "jump" in its per capita human capital and income. Thus, this paper provides an explanation for the East Asian Miracle (or any other trade induced growth miracle), by suggesting that the East Asian economies just started to engage in trade in manufactured goods, and consequently, they experienced very fast economic growth (or "miracle"). Secondly, the model implies that due to the law of diminishing returns in the accumulation of human capital, all countries that have similar underlying structures may converge to the same equilibrium in the long run. Thus, our theoretical implication is also consistent with the empirical finding of conditional convergence.

In what follows, Section 2 sets up the basic analytical framework, Section 3 analyzes the role of product quality in international division of labor, Section 4 extends the basic model to explore the dynamic effects of international trade, and Section 5 offers the conclusion.

\section{The basic analytical framework}

The basic analytical framework is built on Dixit and Stiglitz (1977) with some modifications. Consider an economy in which there is a single consumption good. Every individual in the economy obtains utility from the consumption of both the quality and the quantity of the good and has the following utility function

$$
v(M, Q)
$$

where $M$ and $Q$ denote the consumption of the quantity and the quality of the good, respectively. We assume that an individual consumes at the same quality level. The utility function, $v(M, Q)$, is strictly increasing with respect to both of its variables.

The single (final) consumption good is produced through the costless combination of a variety of differentiated intermediate goods (or processes). The economy is assumed to be able to produce any of a large number of intermediate goods with any level of quality. The production function of the quantity is defined as

$$
X=\left(\sum_{i=1}^{n} x_{i}^{\theta}\right)^{1 / \theta}, \quad 0<\theta<1
$$

where $X$ denotes the quantity of the final output, $x_{i}$ denotes the quantity of the $i$ th intermediate product, $n$ denotes the number of the intermediate products, and $\theta$ measures the degree of substitution between different intermediate products.

We assume that the qualities of different intermediate goods are highly complementary in producing the quality of the final consumption good. The simplest formulation that can capture this property is that the qualities of the intermediate goods are perfectly complementary in producing the quality of the final good, namely

$$
Q=\min \left(Q_{1}, Q_{2}, \ldots, Q_{n}\right)
$$


where $Q_{i}$ denotes the quality of the $i$ th intermediate product and $Q$ denotes the quality of the final consumption good. From the above formulation, obviously, all producers of different intermediate products will produce goods with the same quality in equilibrium, so we might as well denote the quality of every intermediate good by $Q$ as that of the final good.

We assume that there is only one factor of production, which is human capital (or efficiency labor). The human capital here can be interpreted as an index of the combination of the level of industrial technology of firms and the level of workers' educational attainment in the economy. For any intermediate good that is produced, the human capital employed is

$$
h_{i}=\alpha+\beta Q x_{i}
$$

where $\alpha, \beta$ are both positive constants. It should be noted that our only deviation from the Dixit-Stiglitz model here is that we assume that the higher the quality of a product is, the more costly it is to produce it.

Let $N$ be the total number of individuals of this economy. We assume that every individual in this economy is endowed with $h$ amount of human capital, so the total amount of human capital in the economy is $N h$. Full employment requires that

$$
N h=\sum_{i=1}^{n}\left(\alpha+\beta Q x_{i}\right) \text {. }
$$

We assume that the market for the final good is perfectly competitive. Given a quality $Q$, let $P$ be the price of the final good and $p_{i}$ for $i=1,2, \ldots, n$ be the prices of intermediate goods. Then, the cost function for final good producers is

$$
\sum_{i=1}^{n} p_{i} x_{i}
$$

Final good producers seek to minimize their cost for any given amount of output by taking $P$ and $p_{i}$ (for $i=1,2, \ldots, n$ ) as given and choosing the optimal input combination in the production function (1). The first-order condition yields

$$
x_{i}=\left(\frac{p_{i}}{P}\right)^{1 /(\theta-1)}\left(\sum_{i=1}^{n} x_{i}^{\theta}\right)^{1 / \theta} .
$$

Meanwhile, the profit for final goods producers is

$$
\pi=P X-\sum_{i=1}^{n} p_{i} x_{i}=P\left(\sum_{i=1}^{n} x_{i}^{\theta}\right)^{1 / \theta}-\sum_{i=1}^{n} p_{i} x_{i}
$$

Plugging (5) into (6), then the zero profit condition of perfect competition in the final good market implies

$$
P=\left[\sum_{i=1}^{n}\left(p_{i}\right)^{\theta /(\theta-1)}\right]^{(\theta-1) / \theta} .
$$


Now we turn to the problems of the firms producing intermediate goods. We begin by noting that as long as there are more potential varieties of intermediate goods than are actually produced, there will be no reason for more than one firm to produce any given intermediate good in equilibrium; since the varieties of intermediate goods are symmetrical, a firm will always prefer to switch to a different intermediate good rather than compete with another firm. Thus each intermediate good will be produced by a monopolist.

Based on the above analysis, let us consider profit-maximizing pricing behavior of firms. The $i$ th firm will choose its price to maximize its profits, $\pi_{i}$. Noticing (5) and (1), we have

$$
\pi_{i}=p_{i} x_{i}-\left(\alpha+\beta Q x_{i}\right) w=\left[p_{i}^{\theta /(\theta-1)}-\beta Q w p_{i}^{1 /(\theta-1)}\right] X P^{1 /(1-\theta)}-\alpha w
$$

subject to (7), where $w$ is the cost of one unit of human capital or the wage rate of efficiency labor. Following Dixit and Stiglitz, we assume that a single individual firm is sufficiently small so that its decision on pricing its own product will not affect either the total output $(X)$ or the price of the final good $(P)$. Then, from the first order condition, we get

$$
p_{i}=\frac{\beta Q}{\theta} w
$$

Clearly, the price of a product increases as its quality rises.

Next, we introduce the possibility of entry and exit. If firms are free to enter to produce new intermediate goods and exit, then profits in the production of $i$ th intermediate good will be driven to zero. Thus,

$$
\pi_{i}=p_{i} x_{i}-\left(\alpha+\beta Q x_{i}\right) w=\frac{\beta Q}{\theta} w x_{i}-\left(\alpha+\beta Q x_{i}\right) w=0 .
$$

This implies that the output of any intermediate good is

$$
x_{i}=\frac{\alpha \theta}{\beta Q(1-\theta)} .
$$

Thus, the output of any intermediate good that is actually produced decreases as the level of its quality rises.

We assume that the labor market is perfectly competitive, so using the full-employment condition, we can then conclude that the number of firms, which is also the number of intermediate goods actually produced, is

$$
n=\frac{N h}{\alpha+\beta Q x_{i}}=\frac{N h(1-\theta)}{\alpha}
$$

(12) indicates that the fixed cost $\alpha$ limits the number of goods produced. Finally, the total output of the final good is

$$
X=\left(\sum_{i=1}^{n} x_{i}^{\theta}\right)^{1 / \theta}=\left(n x_{i}^{\theta}\right)^{1 / \theta}=\left[\left(\frac{\alpha}{1-\theta}\right)^{1-(1 / \theta)} \frac{\theta}{\beta}\right] \frac{(N h)^{1 / \theta}}{Q} .
$$


For the simplicity of notation, we define

$$
A \equiv\left(\frac{\alpha}{1-\theta}\right)^{1-(1 / \theta)} \frac{\theta}{\beta} .
$$

Thus, we can express (13) in the following simple form

$$
X=A \frac{(N h)^{1 / \theta}}{Q} \text { or } X Q=A(N h)^{1 / \theta} ;
$$

(14) characterizes the trade-off between the production of the quantity and the quality of the final consumption good in this economy. It is easy to see that the graphical illustration of (14) that depicts the trade-off between quantity and quality will be convex. This result is not surprising if we refer to (3) (imagining the case that only one intermediate good is produced), which introduces the formulation of scale economies into the model.

Next, we investigate the determination of quality. Since the market for the final good is perfectly competitive, the quality of the final good is ultimately determined by the representative consumer of the economy. Thus, we can derive the quality of the final good (and hnce the intermediate goods) by solving the problem of a representative individual's utility maximization subject to his budget constraint.

First, we derive a representative individual's budget constraint. Plugging (11) and (12) into (5), and rearranging, we get

$$
p_{i}=\left(\frac{N h(1-\theta)}{\alpha}\right)^{(1-\theta) / \theta} P .
$$

Plugging (15) into (9), we get

$$
\frac{w}{P}=A \frac{(N h)^{(1-\theta) / \theta}}{Q} .
$$

As a representative individual is endowed with " $h$ " amount of human capital, his real income is $w h / P$.

Then, the quantity of an individual's consumption, which is denoted by $M$, is his real income. Namely,

$$
M=\frac{w h}{P}=A \frac{N^{(1-\theta) / \theta} h^{1 / \theta}}{Q},
$$

or

$$
M Q=A N^{(1-\theta) / \theta} h^{1 / \theta} .
$$

Taking the logarithm, we can express the above equation as

$$
\ln M+\ln Q=\ln \left(A N^{(1-\theta) / \theta} h^{1 / \theta}\right),
$$

which is the "budget constraint" of a representative individual of the economy and characterizes the log-linear relationship between the quantity and the quality of consumption.

Now, we further discuss an individual's preferences. To avoid any "corner" solutions, the indifference curves must be more convex than the "budget line (or curve)" generated 
by (16), which is log-linear. Thus, we write the utility function, $v(M, Q)$, in the following form:

$$
u(\ln M, \ln Q),
$$

and we assume that $u($, ) satisfies the following neoclassical properties:

$$
u_{1}(,)>0, \quad u_{2}(,)>0, \quad u_{11}(,)<0, \quad u_{22}(,)<0, \quad u_{12}(,)>0 .
$$

To obtain a closed form solution of an individual's utility maximization, we assume that $u($,$) is homothetic. Then, given the specified utility function and the budget constraint$ (16), we can express an individual's optimal choice of the quantity and the quality of his consumption as

$$
\ln M^{*}=\lambda \ln \left(A N^{(1-\theta) / \theta} h^{1 / \theta}\right) \quad \text { and } \quad \ln Q^{*}=(1-\lambda) \ln \left(A N^{(1-\theta) / \theta} h^{1 / \theta}\right)
$$

or

$$
M^{*}=A^{\lambda} N^{\lambda(1-\theta) / \theta} h^{\lambda / \theta} \quad \text { and } \quad Q^{*}=A^{(1-\lambda)} N^{(1-\lambda)(1-\theta) / \theta} h^{(1-\lambda) / \theta}
$$

where $\lambda$ is a constant, $0<\lambda<1$. It is clear that the quality as well as the quantity that an individual consumes increases with $h$ and $N$.

\section{Quality and international division of labor}

In this section, we will analyze the possibility of trade in manufactured goods between two economies with different levels of individual human capital and economic development. We may regard the richer economy as the whole industrial world, so it is both realistic and convenient to treat the poorer economy as a small economy. In this section, we assume that every individual in the richer economy is endowed with one unit of human capital, every individual in the small poorer economy is endowed with $h^{\mathrm{s}}$ amount of human capital, and

$$
h^{\mathrm{s}}<1 .
$$

We assume that individuals in this small economy differ from those in the industrial world only in the endowment of human capital. They share preferences with individuals of the rest of the world. Also, the firms in this economy have access to the same production functions of any goods as those in the rest of the world. ${ }^{6}$

Individuals in this small economy face two choices of obtaining the single final good to consume. One is to produce the good by joining the global industrial specialization. The other is to produce the good in autarky. First, if individuals in the small economy engages in international trade with the industrial world, they will specialize in some intermediate goods. In this case, as we analyzed in Section 2, they must produce the goods with quality $Q^{*}$ that meet the "international standard" (because of the high complementarity of the qualities of

\footnotetext{
${ }^{6}$ Notice that conceptually, we can incorporate the industrial technology as part of the individuals' human capital of an economy.
} 
intermediate goods in producing the quality of the final good). Also, we assume that there is neither trade barrier nor transport cost. Suppose that the population of the industrial world is $N$. Then, from the analysis in Section 2, the (real) wage rate in terms of the final good with quality $Q^{*}$ is

$$
w\left(Q^{*}\right)=A \frac{N^{(1-\theta) / \theta}}{Q^{*}} .
$$

It should be noted that our assumption that the economy is "small" implies that we can ignore the impact of its participation in the global industrial specialization on the determination of the product quality, $Q^{*}$, and on the real wage rate in the industrial countries. Consequently, an individual's real income in this small economy will be

$$
I^{1} \equiv w\left(Q^{*}\right) h^{\mathrm{s}} \text {. }
$$

Thus, if this economy participates in the global industrial specialization, an individual's utility in the economy, which is denoted by $U^{1}$, will be

$$
U^{1} \equiv u\left(\ln \left(w\left(Q^{*}\right) h^{\mathrm{s}}\right), \ln Q^{*}\right) .
$$

Second, individuals in this small economy can also produce the consumption good in autarky. In this case, they can produce the good with the quality that they optimally choose. However, in autarky, individuals in the economy will have to use a less efficient, or "inferior" production technology (or a "cottage technology" in terms of Murphy et al., 1989). ${ }^{7}$ This "inferior" autarkic production technology, which has constant returns to scale, is described as

$$
Y=\phi \frac{H}{Q}
$$

where $Y$ and $H$ denote the quantity of the output of the final consumption good with quality $Q$ and the efficiency labor input respectively, and $\phi$ is a positive constant. We assume that the labor market in this small economy is perfectly competitive, so the wage rate (in terms of the final good with quality $Q$ ) that an individual receives in autarky is the marginal product of efficiency labor, namely,

$$
\frac{\phi}{Q} \text {. }
$$

As the autarkic production technology is "inferior" to the production technology of global industrial specialization, we assume that the marginal productivity in autarky is lower at producing goods of any given quality, that is,

$$
\frac{\phi}{Q}<w(Q)=A \frac{N^{(1-\theta) / \theta}}{Q} \text {. }
$$

\footnotetext{
${ }^{7}$ Fan (2004) explores an alternative modelling strategy by assuming that all economies use the same production technologies of increasing returns.
} 
Rearranging the above equation yields the following technical assumption:

$$
\phi<A N^{(1-\theta) / \theta} \text {. }
$$

In autarky, clearly, an individual's income in this economy is

$$
\frac{\phi}{Q} h^{\mathrm{s}}
$$

so his budget constraint is

$$
M=\frac{\phi}{Q} h^{\mathrm{s}},
$$

or

$$
\ln M+\ln Q=\ln \phi h^{\mathrm{s}} .
$$

Because $u($,$) is homothetic, an individual's optimal consumption bundle, in this case, is$

$\ln M=\lambda \ln \phi h^{\mathrm{s}}, \quad$ and $\quad \ln Q=(1-\lambda) \ln \phi h^{\mathrm{s}}$.

Correspondingly, an individual's utility in autarky, which is denoted by $U^{2}$, is

$$
U^{2} \equiv u\left(\lambda \ln \phi h^{\mathrm{s}},(1-\lambda) \ln \phi h^{\mathrm{s}}\right) .
$$

Clearly, individuals in this small economy will participate in global industrial specialization if and only if

$$
U^{1} \geq U^{2}
$$

namely

$$
u\left(\ln w\left(Q^{*}\right) h^{\mathrm{s}}, \ln Q^{*}\right) \geq u\left(\lambda \ln \phi h^{\mathrm{s}},(1-\lambda) \ln \phi h^{\mathrm{s}}\right) .
$$

Then, we have the following proposition.

Proposition 1. There exists a threshold level of human capital, $h^{c}$, such that an economy will participate in international industrial specialization if and only if the level of its representative individual's human capital is above $h^{c}$.

Proof. From the above analysis, we know that if an economy participates in the global industrial specialization, its representative individual's utility is

$$
u\left(\ln \left(w\left(Q^{*}\right) h^{\mathrm{s}}\right), \ln Q^{*}\right)
$$

while in autarky, its representative individual's utility is

$$
u\left(\lambda \ln \left(\phi h^{\mathrm{s}}\right),(1-\lambda) \ln \left(\phi h^{\mathrm{s}}\right)\right) .
$$

Now, we define

$$
G \equiv u\left(\ln \left(w\left(Q^{*}\right) h^{\mathrm{s}}\right), \ln Q^{*}\right)-u\left(\lambda \ln \left(\phi h^{\mathrm{s}}\right),(1-\lambda) \ln \left(\phi h^{\mathrm{s}}\right)\right) .
$$


Then, the economy will engage in trade if and only if

$$
G \geq 0 \text {. }
$$

To prove Proposition 1, we will try to find out under what conditions we will have $G \geq 0$. First, noticing (21) and $h^{\mathrm{s}}<1$, we have

$$
\ln Q^{*}=(1-\lambda) \ln \left(A N^{(1-\theta) / \theta}\right)>(1-\lambda) \ln \left(\phi h^{\mathrm{s}}\right) .
$$

So if

$$
\ln \left(w\left(Q^{*}\right) h^{\mathrm{s}}\right) \geq \lambda \ln \left(\phi h^{\mathrm{s}}\right),
$$

namely

$$
h^{\mathrm{s}} \geq \exp \frac{\lambda \ln \phi-\ln w\left(Q^{*}\right)}{1-\lambda},
$$

then, clearly, the economy will join the international industrial specialization.

In the following, we will discuss the case when

$$
\ln \left(w\left(Q^{*}\right) h^{\mathrm{s}}\right)<\lambda \ln \left(\phi h^{\mathrm{s}}\right),
$$

namely

$$
h^{\mathrm{s}}<\exp \frac{\lambda \ln \phi-\ln w\left(Q^{*}\right)}{1-\lambda} .
$$

In this case,

$$
\begin{aligned}
\frac{\mathrm{d} G}{\mathrm{~d} h^{\mathrm{s}}}= & \frac{1}{h^{\mathrm{s}}} u_{1}\left(\ln \left(w\left(Q^{*}\right) h^{\mathrm{s}}\right), \ln Q^{*}\right)-\frac{\lambda}{h^{\mathrm{s}}} u_{1}\left(\lambda \ln \left(\phi h^{\mathrm{s}}\right),(1-\lambda) \ln \left(\phi h^{\mathrm{s}}\right)\right) \\
& -\frac{1-\lambda}{h^{\mathrm{s}}} u_{2}\left(\lambda \ln \left(\phi h^{\mathrm{s}}\right),(1-\lambda) \ln \left(\phi h^{\mathrm{s}}\right)\right) \\
= & \frac{1}{h^{\mathrm{s}}}\left[u_{1}\left(\ln \left(w\left(Q^{*}\right) h^{\mathrm{s}}\right), \ln Q^{*}\right)-\lambda u_{1}\left(\lambda \ln \left(\phi h^{\mathrm{s}}\right),(1-\lambda) \ln \left(\phi h^{\mathrm{s}}\right)\right)\right. \\
& \left.-(1-\lambda) u_{2}\left(\lambda \ln \left(\phi h^{\mathrm{s}}\right),(1-\lambda) \ln \left(\phi h^{\mathrm{s}}\right)\right)\right] .
\end{aligned}
$$

Now, noticing that the "slope" of the budget constraint

$$
\ln M+\ln Q=\ln \left(\phi h^{\mathrm{s}}\right)
$$

is equal to -1 , the first order condition from an individual's optimal choice of the quantity and the quality of consumption in autarky entails

$$
u_{1}\left(\lambda \ln \left(\phi h^{\mathrm{s}}\right),(1-\lambda) \ln \left(\phi h^{\mathrm{s}}\right)\right)=u_{2}\left(\lambda \ln \left(\phi h^{\mathrm{s}}\right),(1-\lambda) \ln \left(\phi h^{\mathrm{s}}\right)\right) .
$$

Thus,

$$
\begin{aligned}
\frac{\mathrm{d} G}{\mathrm{~d} h^{\mathrm{s}}} & =\frac{1}{h^{\mathrm{s}}}\left[u_{1}\left(\ln \left(w\left(Q^{*}\right) h^{\mathrm{s}}\right), \ln Q^{*}\right)-(\lambda+1-\lambda) u_{1}\left(\lambda \ln \left(\phi h^{\mathrm{s}}\right),(1-\lambda) \ln \left(\phi h^{\mathrm{s}}\right)\right)\right] \\
& =\frac{1}{h^{\mathrm{s}}}\left[u_{1}\left(\ln \left(w\left(Q^{*}\right) h^{\mathrm{s}}\right), \ln Q^{*}\right)-u_{1}\left(\lambda \ln \left(\phi h^{\mathrm{s}}\right),(1-\lambda) \ln \left(\phi h^{\mathrm{s}}\right)\right)\right]
\end{aligned}
$$




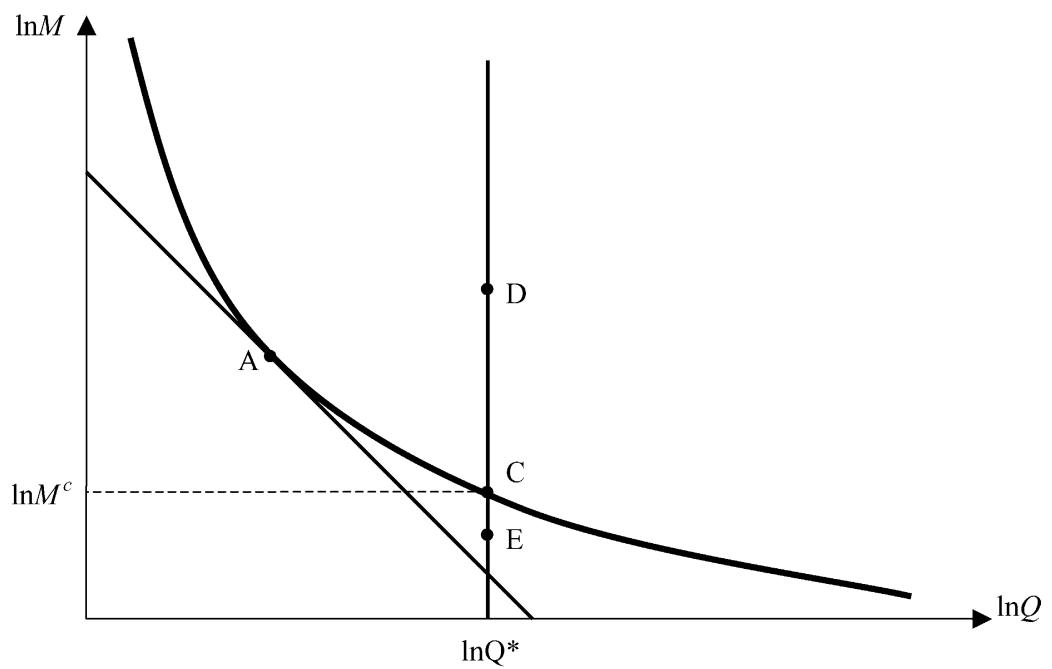

Fig. 1. The country will join global industrial specialization if and only if its per worker output (with $Q^{*}$ ) is above point "C".

Noticing that $\ln Q^{*}>(1-\lambda) \ln \left(\phi h^{\mathrm{s}}\right)($ see $(22))$, and in this case, $\ln \left(w\left(Q^{*}\right) h^{\mathrm{s}}\right)<\lambda \ln \left(\phi h^{\mathrm{s}}\right)$, by $u_{11}()<$,0 , and $u_{12}()>$,0 (from (17)), we have

$$
u_{1}\left(\ln \left(w\left(Q^{*}\right) h^{\mathrm{s}}\right), \ln Q^{*}\right)>u_{1}\left(\lambda \ln \left(\phi h^{\mathrm{s}}\right), \ln Q^{*}\right)>u_{1}\left(\lambda \ln \left(\phi h^{\mathrm{s}}\right),(1-\lambda) \ln \left(\phi h^{\mathrm{s}}\right)\right) .
$$

Therefore,

$$
\frac{\mathrm{d} G}{\mathrm{~d} h^{\mathrm{s}}}>0
$$

Recalling that we proved when $h^{\mathrm{s}}=\exp \left(\lambda \ln \phi-\ln w\left(Q^{*}\right)\right) /(1-\lambda), G>0$. Thus, there exists a $h^{\mathrm{c}}, h^{\mathrm{c}} \in\left[0, \exp \left(\lambda \ln \phi-\ln w\left(Q^{*}\right)\right) /(1-\lambda)\right]$, such that $G(h) \geq 0$ if and only if $h \geq$ $h^{\mathrm{c}}$. In other words, there exists a threshold level of human capital, $h^{\mathrm{c}}$, such that an economy will participate in international industrial specialization if and only if its representative individual's human capital is above this threshold level.

The intuition of Proposition 1 can be best illustrated in Fig. 1. From Fig. 1, notice that (1) point " $\mathrm{A}$ " is the consumption bundle that a representative individual will choose in autarky, and (2) point " $\mathrm{C}$ " is the intersection between the indifference curve that is tangent to the "budget line" from autarkic production and the vertical line, " $Q=Q^{*}$ ". Then, we can see that an economy will engage in trade and specialization if and only if a representative individual of the economy can consume more quantity of goods with quality $Q^{*}$ than at the critical point "C." In other words, the indifference curve passing through the point that represents the consumption bundle when engaging in trade is above that when remaining in autarky if and only if that point is above "C."

For example, if the consumption bundle is at point " $\mathrm{D}$," which is above "C," then a representative individual of the economy will obtain higher utility by participating in global 
industrial specialization. In this case, the economy will engage in trade. On the other hand, if the consumption bundle is at point " $\mathrm{E}$," which is below " $\mathrm{C}$," then the economy will remain autarkic. The intuition of the proposition is that the more an individual in the small economy can produce at " $Q=Q^{*}$," the closer its optimal choice of quality is to that of the industrial world, and hence the more likely the economy is to join the global industrial specialization.

Proposition 1 indicates that the division of labor may be hampered by the heterogeneity of human capital. In the international context, when the level of per capita human capital of an economy is sufficiently low relative to that in the rest of the world, individuals in the economy would choose to remain autarkic to produce more quantity of low-quality goods rather than join the international industrial specialization to produce high-quality goods. Empirically, for example, Korea and Taiwan both greatly raised their literacy rates in the 1950 s, prior to their rapid expansion of exports in manufactured goods in the 1960s (e.g. Wood, 1994).

The above analysis also has an interesting policy implication. In an important paper, Buchanan (1994) links work ethics with increasing returns. He proposes that if everyone works more, the extent of the market will increase, enabling a higher degree of division of labor and hence higher productivity. However, by examining the validity and significance of this hypothesis in the framework of inframarginal analysis of Yang and $\mathrm{Ng}(1993), \mathrm{Ng}$ and Ng (2003) show that Buchanan's thesis has more relevance in ancient times when the work ethics originated but is less significant in the modern world.

In a vein similar to Buchanan, this paper has the following policy implication. If rich economies transfer some resources to poor economies to help them develop their educational infrastructure, individuals in poor economies will accumulate more human capital so that the poor economies may switch their production from autarky to international specialization. Due to the increased size of the market, everyone in the rich economies as well as the poor economies will be better off. Thus, the transfer of some resources from rich to poor countries can lead to an outcome of Pareto improvement for all countries. Therefore, for example, it implies that the large number of scholarships provided by rich countries to the students in poor countries may benefit both the rich and the poor countries even if those students go back to their home country after their study in the rich countries.

Next, we have the following corollary.

Corollary 1. $h^{c}$ is a strictly decreasing function of $\lambda$.

Proof. From the analyses in Section 2, we know that when $h=1$,

$$
w\left(Q^{*}\right)=A^{\lambda} N^{(\lambda(1-\theta)) / \theta},
$$

so

$$
\frac{\mathrm{d} \ln \left[w\left(Q^{*}\right)\right]}{\mathrm{d} \lambda}=\ln A+\frac{(1-\theta)}{\theta} \ln N .
$$

From the proof of Proposition 1, we know

$$
\begin{aligned}
\frac{\mathrm{d} G}{\mathrm{~d} \lambda}= & \frac{\mathrm{d} \ln \left[w\left(Q^{*}\right)\right]}{\mathrm{d} \lambda} u_{1}\left(\ln \left(w\left(Q^{*}\right) h^{\mathrm{s}}\right), \ln Q^{*}\right)-\ln \left(\phi h^{\mathrm{s}}\right) u_{1}\left(\lambda \ln \left(\phi h^{\mathrm{s}}\right),(1-\lambda) \ln \left(\phi h^{\mathrm{s}}\right)\right) \\
& +\ln \left(\phi h^{\mathrm{s}}\right) u_{2}\left(\lambda \ln \left(\phi h^{\mathrm{s}}\right),(1-\lambda) \ln \left(\phi h^{\mathrm{s}}\right)\right) .
\end{aligned}
$$


From the proof of Proposition 1, we also know

$$
u_{1}\left(\lambda \ln \left(\phi h^{\mathrm{s}}\right),(1-\lambda) \ln \left(\phi h^{\mathrm{s}}\right)\right)=u_{2}\left(\lambda \ln \left(\phi h^{\mathrm{s}}\right),(1-\lambda) \ln \left(\phi h^{\mathrm{s}}\right)\right)
$$

so

$$
\frac{\mathrm{d} G}{\mathrm{~d} \lambda}=\left[\ln A+\frac{(1-\theta)}{\theta} \ln N\right] u_{1}\left(\ln \left(w\left(Q^{*}\right) h^{\mathrm{s}}\right), \ln Q^{*}\right)>0 .
$$

Thus, from $G\left(h^{\mathrm{c}}, \lambda\right)=0$, we have

$$
\frac{\mathrm{d} h^{\mathrm{c}}}{\mathrm{d} \lambda}=-\frac{\mathrm{d} G / \mathrm{d} \lambda}{\mathrm{d} G / \mathrm{d} h^{\mathrm{c}}}<0 .
$$

This corollary implies that ceteris paribus, the smaller $\lambda$ is, the greater $h^{\mathrm{c}}$ will be, and hence the less likely that the small economy will engage in trade and specialization. The intuition is that if a smaller proportion of income is devoted to "quantity" of consumption and hence more is devoted to "quality" of consumption, there will be a greater "distance" between the ideal quality of consumption between the poor country and the rich country. Consequently, the poor economy will be less likely to join the rich economy in specialization and exchange.

\section{The dynamic effects of trade}

The purpose of this section is to extend the previous analyses to examine the dynamic effects of international trade. In particular, like Ventura, we will try to build a model that can explain both the East Asian Miracle and the empirical finding of conditional convergence.

To extend the previous analysis into a dynamic setting, we assume that every individual lives for one period. At the end of the period, every individual gives birth to a child, so the economy lasts indefinitely.

The analysis of individuals' behavior in each period in this section will be based on the analyses of the previous sections, except that we will no longer assume that an individual's human capital is exogenously given. In this model, we emphasize that human capital, which can be generally interpreted to include industrial technology, is the engine of growth. The analysis of the endogenous formation and evolution of individuals' human capital in this section will build on [Lucas $(1988,1993)]$ with significant simplifications and modifications.

An individual's human capital is assumed to be determined by two (general) factors: one is the time he devotes to accumulate human capital, which is denoted by $e$, and the other is his learning environment, which is denoted by $\Phi$. Specifically, we assume that the human capital formation function takes the following Cobb-Douglas form,

$$
h_{t}=b \mathrm{e}_{t}^{1-a} \Phi_{t}^{a}
$$

where $a, b$ are both positive constants, $a<1$; the subscript $t$ refers to generation $t$ (or period $t$ ). For example, $h_{t}$ refers to the level of human capital of an individual of generation $t$. 
We assume that there are three elements that influence an individual's learning environment in the small economy: the first is the average human capital of his last generation, ${ }^{8}$ the second is the average human capital of the industrial (or developed) world, and the third is the closeness of the contact of the small economy with the rest of the world at the time of the individual's human capital accumulation, which is denoted by $\eta$. The above formulation, in essence, is very similar to [Lucas $(1993,1988)$ ] if we interpret the first factor as the internal effect and the second factor as the external effect. The only difference is the third factor $\eta$. In the Lucas model, every individual (or country) benefits the same from the external effect. In the current model, however, what benefits a small developing economy gains from the industrial world will depend on the closeness of its contact with the industrial world.

Formally, the learning environment of an individual of generation $t$ is described as

$$
\Phi_{t}=g\left(h_{t-1}, h^{*}, \eta_{t}\right)
$$

where $g()$ is a function that is non-decreasing of any of its variables; $h^{*}$ denotes the average human capital of the industrial world. Since the focus of the analysis is on the economies that are in the process of economic development, for simplicity, we assume that the human capital of the representative individual of the rich economy is already in the long-run equilibrium so that $h^{*}$ is constant over time.

In this model, the degree that an economy interacts with the rest of the world is measured by the degree of its participation in international industrial specialization. If an economy is autarkic in producing manufactured goods, the economy will have no contact with the advanced technology in the industrial countries. Thus, it will benefit little from the technological spillover from the rest of the world. On the other hand, if an economy joins the global industrial specialization, as a large body of empirical literature shows, it will benefit much from the technological spillover from industrial nations [(e.g. Evenson and Westphal, 1995; Miller and Upadhyay, 2000)]. Also, Haberler (1988, p. 27) notes,

"(T)rade is the means and vehicle for the dissemination of technological knowledge, the transmission of ideas, for the importation of know-how, skills, managerial talents and entrepreneurship."

Since we abstract from the consideration of the heterogeneity of individuals' human capital (or firms' technology) within an economy, as shown in the last section, the poor economy will either fully participate in the global industrial specialization or be fully autarkic in producing manufactured goods. Thus, $\eta_{t}$ only takes two values and is defined as

$$
\eta_{t}= \begin{cases}0, & \text { if the economy is autarkic at period } t-1 \\ \delta, & \text { if the economy exports manufactured good at period } t-1\end{cases}
$$

where $\delta$ is a positive constant.

\footnotetext{
${ }^{8}$ The average human capital of the last generation is important for an individual's human capital formation particularly because it determines the amount of human capital that the individual can accumulate through "on the job training". The importance of on the job training in individuals' productivity is stressed in the literature of human capital theory (e.g. Becker, 1975) and the "new" growth theory [(e.g. Lucas, 1988, 1993)]. For a more recent theoretical analysis on this issue, see Kremer and Thomson (1998).
} 
We normalize an individual's life span to be one unit of time, which is divided into working and learning. Thus, if an individual devotes $e_{t}$ amount of time in accumulating human capital, he will devotes $1-e_{t}$ amount of time in working. Suppose that the wage rate (of human capital) is denoted by $w_{j}(j=1,2)$, where $w_{j}$ denotes the international wage rate if $j=1$; the autarkic wage rate if $j=2$. Then, an individual's total (life-time) income can be expressed as

$$
\left(1-e_{t}\right) h_{t} w_{j}
$$

namely

$$
\left(1-e_{t}\right) e_{t}^{1-a} g\left(h_{t-1,} h^{*}, \eta_{t}\right) w_{j}
$$

From the previous analysis, it is easy to see that an individual's maximizing his utility entails his maximizing his income. From (25), we can see that $e_{t}$ is the only choice variable of an individual of generation $t$. Also, noticing that neither $g\left(h_{t-1,} h^{*}, \eta_{t}\right)$ nor $w_{j}$ depends on $e_{t}$, then, from the first-order condition of maximizing (25) with respect to $e_{t}$, we have

$$
e_{t}=\frac{1-a}{2-a} \text {. }
$$

Plugging (26) into (23), we get

$$
h_{t}=b\left(\frac{1-a}{2-a}\right)^{1-a} \Phi_{t}^{a} .
$$

For simplicity of notation, we define

$$
\gamma \equiv b\left(\frac{1-a}{2-a}\right)^{1-a} .
$$

Therefore, we can rewrite (27) as

$$
h_{t}=\gamma \Phi_{t}^{a} .
$$

Now, we assume the formulation of an individual's learning environment to have the following Cobb-Douglas form,

$$
\Phi_{t}=B\left(\eta_{t}\right) h_{t-1}^{1-\eta_{t}}\left(h^{*}\right)^{\eta_{t}}
$$

where $B()$ is a non-decreasing function of $\eta$. In particular, since $\eta$ only takes two values in the model, $B(\eta)$ also only takes two values, and $B(\delta) \geq B(0)$. Also, since a representative individual's human capital in a developing country is less than that in the industrial world, namely, $h_{t}<h^{*}$, (29) implies that the greater $\eta_{t}$ is, the greater $\Phi_{t}$ will be. Namely, the more closely the economy interacts with the industrial world, the better the learning environment the next generation of the economy will have. Plugging (29) into (28), we have

$$
h_{t}=\gamma B^{a}\left(\eta_{t}\right) h_{t-1}^{a \eta_{t}}\left(h^{*}\right)^{a\left(1-\eta_{t}\right)},
$$


namely

$$
h_{t}=\left\{\begin{array}{lc}
\gamma B^{a}(0) h_{t-1}^{a}, & \text { if the economy is autarkic at period } t-1 \\
\gamma B^{a}(\delta) h_{t-1}^{a \delta}\left(h^{*}\right)^{a(1-\delta)}, & \text { if the economy exports manufactured } \\
\text { good at period } t-1 .
\end{array}\right.
$$

From (31), clearly, there are two equilibria of the above dynamic system. Firstly, the equilibrium $h^{*}$ is determined by

$$
h^{*}=\gamma B^{a}(\delta)\left(h^{*}\right)^{a \delta}\left(h^{*}\right)^{a(1-\delta)} .
$$

(32) yields

$$
h^{*}=\left[\gamma B^{a}(\delta)\right]^{1 /(1-a)} .
$$

On the other hand, if an economy chooses to be autarkic in the initial period, its representative individual's human capital may converge to a different equilibrium. Let $h^{\prime}$ denote this equilibrium; then it must satisfy

$$
h^{\prime}=\gamma B^{a}(0)\left(h^{\prime}\right)^{a} .
$$

(34) yields

$$
h^{\prime}=\left[\gamma B^{a}(0)\right]^{1 /(1-a)} .
$$

Next, similar to Proposition 1, we have the following lemma.

Lemma 1. There exists a critical level of human capital, $h^{c c}$, such that individuals of generation tin the small economy will participate in the international industrial specialization if and only if

$$
h_{t} \geq h^{c c} \text {. }
$$

Proof. From Proposition 1 and the previous analyses, we know that if $h^{*}$ is normalized to be one, then there exists a threshold level of human capital, $h^{\mathrm{c}}$, such that an economy will participate in international industrial specialization if and only if the level of its representative individual's human capital is above this threshold level. Therefore, when $h^{*}$ is re-scaled to be $\left[\gamma B^{a}(\delta)\right]^{1 /(1-a)}$, as implied by (33), the new threshold level will be

$$
h^{\mathrm{cc}}=\left[\gamma B^{a}(\delta)\right]^{1 /(1-a)} h^{\mathrm{c}} \text {. }
$$

From Lemma 1, we can express (31) as

$$
h_{t}= \begin{cases}\gamma B^{a}(0) h_{t-1}^{a}, & \text { if } h_{t-1}<h^{c c} \\ \gamma B^{a}(\delta) h_{t-1}^{a \delta}\left(h^{*}\right)^{a(1-\delta)}, & \text { if } h_{t-1} \geq h^{\mathrm{cc}} .\end{cases}
$$




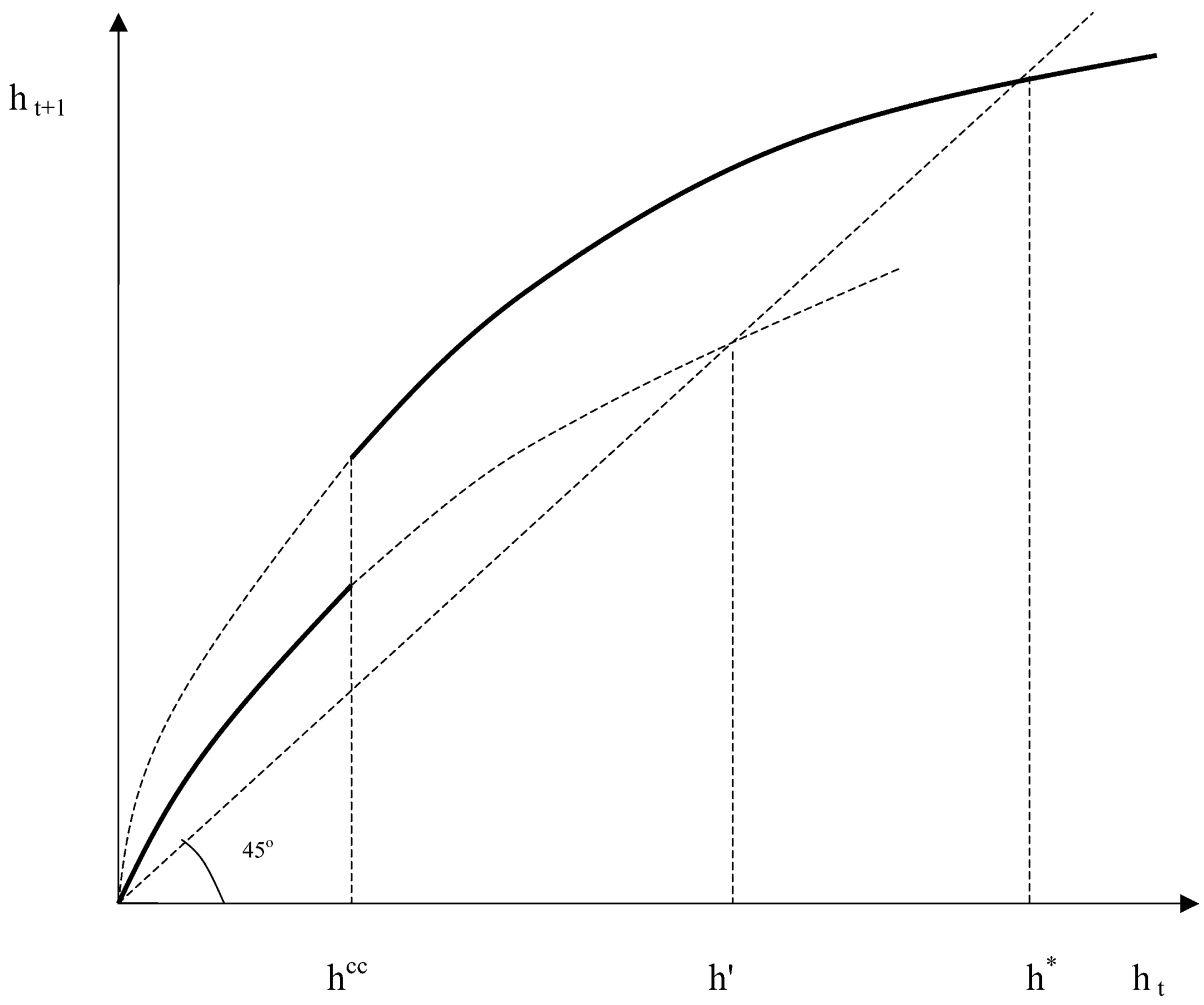

Fig. 2. One equilibrium.

Furthermore, plugging (33) into (36), we get

$$
h_{t}= \begin{cases}\gamma B^{a}(0) h_{t-1}^{a}, & \text { if } h_{t-1}<h^{\mathrm{cc}} \\ {\left[\gamma B^{a}(\delta)\right]^{(1-a \delta) /(1-a)} h_{t-1}^{a \delta},} & \text { if } h_{t-1} \geq h^{\mathrm{cc}} .\end{cases}
$$

Depending on the value of the parameters, the dynamics of the evolution of an individual's human capital of different generations in the economy, which is characterized by (36) or (37), can be illustrated by Fig.2 or Fig.3.

Then, from Figs. 2 and 3, clearly, we have the following proposition.

\section{Proposition 2.}

(1) $h^{*}$ is the only equilibrium if and only if

$$
h^{c c} \leq h^{\prime}
$$

(2) $h^{*}$ and $h^{\prime}$ will be the two equilibria if

$$
h^{c c}>h^{\prime} \text {. }
$$

From either Fig. 2 or Fig. 3, we can see that the evolutions of the human capital of the economy when $h_{t-1}<h^{\mathrm{cc}}$ and when $h_{t-1} \geq h^{\mathrm{cc}}$ follow two different paths. Namely, there 


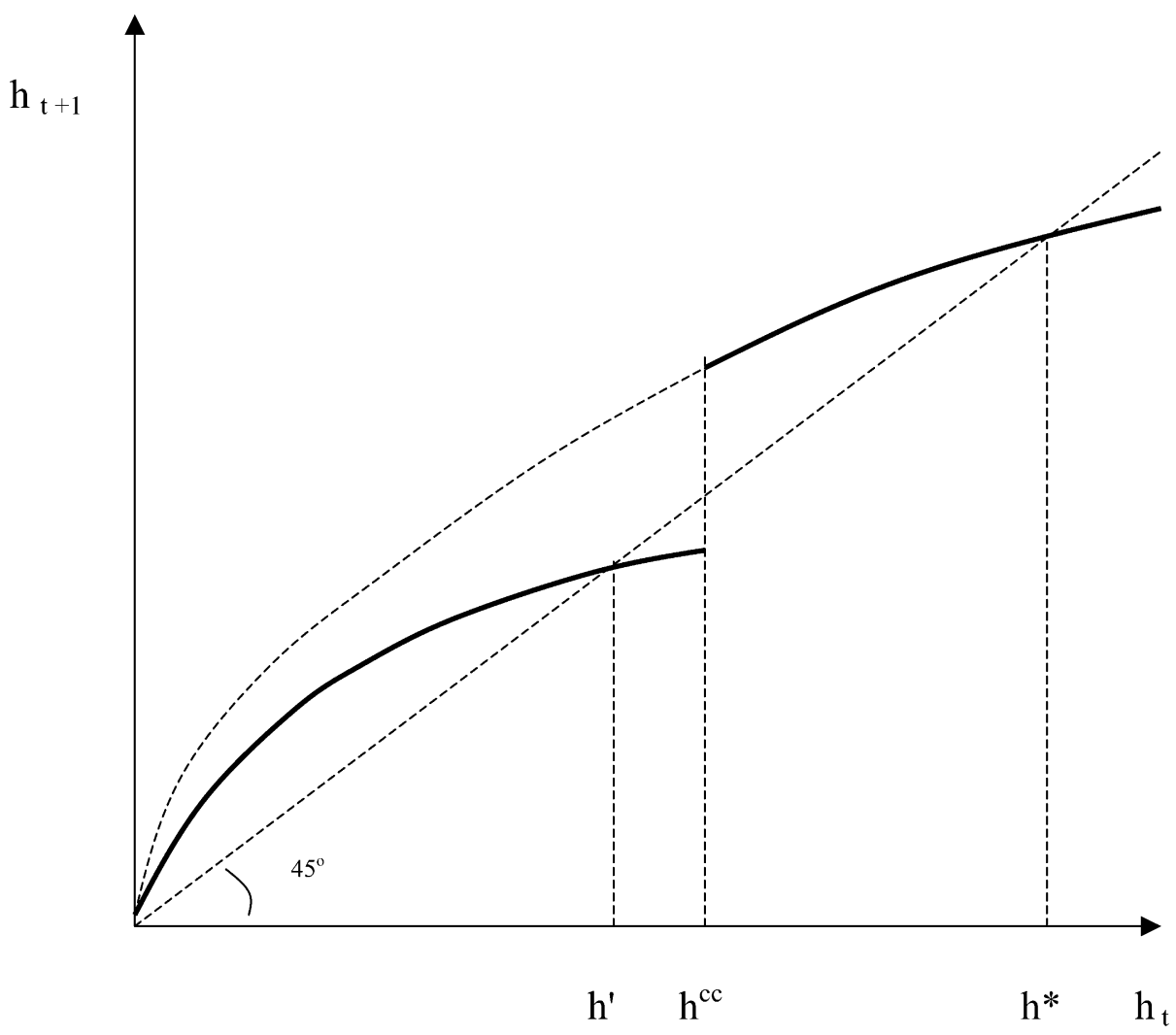

Fig. 3. Two equilibria.

is a discrete "jump" in the evolution of an individual's human capital when the average level of human capital of the previous generation reaches $h^{\mathrm{cc}}$. Thus, Proposition 2 implies that there exists a threshold level of human capital accumulation and economic development.

This proposition sheds light on both the East Asian Miracle and the empirical finding of conditional convergence. Firstly, Lemma 1 indicates that a poor economy with very low average level of human capital may choose to produce low-quality manufactured goods in autarky. In this case, it will have a relatively low growth rate. Meanwhile, under the condition $h^{\mathrm{cc}} \leq h^{\prime}$, the economy will gradually develop through human capital accumulation, and its average level of human capital will ultimately reach the threshold level, $h^{\mathrm{cc}}$. Then, again by Lemma 1, the economy will begin to produce and export high-quality manufactured goods and engage in trade and specialization. Meanwhile, when the average level of human capital of the previous generation reaches $h^{\mathrm{cc}}$, the economy will experience a "jump" in its per capita human capital and income (see Fig. 2). Thus, this paper provides an explanation for the East Asian Miracle (or any other trade induced growth miracle) by suggesting that the East Asian economies just started to engage in trade in manufactured goods, and consequently, they experienced very fast economic growth (or "miracle"). 
Secondly, under the condition, $h^{\mathrm{cc}} \leq h^{\prime}$, from Fig. 2, we can see that due to the law of diminishing returns in the accumulation of human capital, all countries will converge to the same equilibrium in the long run. Therefore, our theoretical implication is also consistent with the empirical finding of conditional convergence.

Part (1) of Proposition 2 also has other interesting growth implications. It implies that middle income countries may have the highest economic growth rates even though all economies will converge to the same equilibrium in the long run. Meanwhile, it helps explain why the newly industrial countries, which have the highest economic growth rates, also have the fastest growth in exports (e.g. Lucas, 1993).

Finally, Part (2) of Proposition 2 implies that if $h^{\mathrm{cc}}>h^{\prime}$, there are two stable equilibria that are associated with autarky and full-scale trade respectively (see Fig. 3). This result has an important policy implication. As individual firms ignore the externality effects of participating in global industrial specialization, there is a disparity between the social return and the private return for individual firms. So, to promote a country's growth (in particular, to avoid the possible "poverty trap" in Fig. 3), the government of a poor economy may choose to subsidize certain industries to encourage them to export high-quality manufactured goods to rich countries. ${ }^{9}$ When these industries that receive export subsidy from the government choose to produce and export high-quality products, the technological spillovers from the industrial countries will make them develop much more quickly. Meanwhile, other domestic industries will also benefit from the technological spillover from these exporting industries and hence will facilitate other industries' participation in the international industrial specialization. Thus, this analysis provides an explanation for the promotion of a fraction of leading export industries as a development strategy, one that was successfully adopted in several East Asian countries. ${ }^{10}$

\section{Conclusion}

This paper analyzes the roles of product quality and increasing returns in the international division of labor and economic development. A key assumption is that in the modern production of specialization, the qualities of different intermediate goods are highly complementary in producing the quality of the final good. Meanwhile, as the demand for quality increases with income, there is a conflict in the preferences for the ideal quality of consumption between rich and poor countries. Therefore, despite the higher efficiency of international specialization in the production of the goods of any quality, a poor country may choose an "inferior" autarkic production technology to produce more quantity, rather than join the global markets by specializing in producing some intermediate goods of the high quality of international standard. In other words, due to the heterogeneity of human capital, the degree of the division of labor is limited by the limited extent of the market.

\footnotetext{
${ }^{9}$ Note that the existence of increasing returns and non-convexity often has interesting policy implications (e.g. see the recent survey and analyses by $\mathrm{Ng}$, 2003). In fact, Galor (1996) shows that under some circumstances, policies may matter even without increasing returns and non-convexity.

${ }^{10}$ For example, see Amsden (1989) for the discussion on the experience of Korea, and Wade (1990) for the discussion on the experience of Taiwan.
} 
In the international context, trade in manufactured goods does not occur between countries with very different levels of per capita human capital or income.

This model also examines the dynamic effects of international trade, shedding light on the patterns of cross-country growth. In particular, it complements the existing literature in explaining both the East Asian Miracle and the conditional convergence finding. Firstly, the analysis implies that a poor economy with a very low average level of human capital will choose to produce low-quality manufactured goods in autarky, so it will have relatively low growth rate. Meanwhile, under some reasonable conditions, the poor economy will gradually develop through human capital accumulation, and its average level of human capital will ultimately reach the threshold level of participating in international industrial specialization. When the threshold level is reached, the model shows that the economy will experience a "jump" in its per capita human capital and income. Thus, this paper provides an explanation for the East Asian Miracle by suggesting that the East Asian economies just started to engage in trade in manufactured goods, and consequently, they experienced very fast economic growth. Secondly, under some reasonable conditions, the model implies that due to the law of diminishing returns in the accumulation of human capital, all countries that have similar underlying structures will converge to the same equilibrium in the long run. Thus, our theoretical implication is also consistent with the empirical finding of conditional convergence. Finally, this paper yields several interesting policy implications.

\section{Acknowledgements}

I am grateful to Yew-Kwang Ng for valuable comments and to Debra Dove for editorial help. All remaining errors are entirely my own.

\section{References}

Amsden, A., 1989. Asia's Next Giant: South Korea and Late Industrialization. Oxford University Press, Oxford. Barro, R.J., Sala-i-Martin, X., 1995. Economic Growth. McGraw-Hill, New York.

Becker, G.S., 1975. Human Capital: A Theoretical and Empirical Analysis, With Special Reference to Education. Columbia University Press, New York.

Becker, G.S., Murphy, K.M., 1992. The division of labor, coordination costs, and knowledge. Quarterly Journal of Economics 107, 1137-1160.

Buchanan, J.M., 1994. The supply of labor and the extent of the market. In: Buchanan, J.M., Yoon, Y.J. (Eds.), The Returns to Increasing Returns. University of Michigan Press, Ann Arbor, pp. 331-342.

Copeland, B.R., Kotwal, A., 1997. Quality-biased technical progress and North-South trade. Journal of International Trade and Economic Development 6, 1-14.

Dixit, A.K., Stiglitz, J.E., 1977. Monopolistic competition and optimum product diversity. American Economic Review 67, 297-308.

Ethier, W., 1982. National and international returns to scale in the modern theory of international trade. American Economic Review 72, 389-405.

Evenson, R.E., Westphal, L.E., 1995. Technological change and technology strategy. In: Behrman, J., Srinivasan, T.N. (Eds.), Handbook of Development Economics, vol. 3A. North Holland. Amsterdam, pp. 2209-2299.

Fan, C.S., 2004. Increasing returns, product quality, and international trade. Mimeo, Lingnan University.

Galor, O., 1996. Convergence? Inferences from theoretical models. Economic Journal 106, 1056-1069. 
Galor, O., Mountford, A., 2003. Trade, demographic patterns and the great divergence: why are one third of people Indian or Chinese? Mimeo, Brown University.

Grossman, G., Helpman, E., 1991. Innovation and Growth in the Global Economy. MIT Press, Cambridge, MA.

Haberler, G., 1988. International Trade and Economic Development. International Center for Economic Growth, San Francisco.

Kelly, M., 1997. The dynamics of Smithian growth. Quarterly Journal of Economics 112, 939-964.

Kremer, M., 1993. The O-ring theory of economic development. Quarterly Journal of Economics 108, 551-575.

Kremer, M., Thomson, J., 1998. Why isn't convergence instantaneous? Young workers, old workers, and gradual adjustment. Journal of Economic Growth 3, 5-28.

Krugman, P.R., 1979. Increasing returns, monopolistic competition, and international trade. Journal of International Economics 9, 469-479.

Lucas, R.E., 1988. On the mechanics of economic development. Journal of Monetary Economics 22, 3-42.

Lucas, R.E., 1993. Making a miracle. Econometrica 61, 251-272.

Mankiw, N.G., Romer, D., Weil, D.N., 1992. A contribution to the empirics of economic growth. Quarterly Journal of Economics 107, 407-437.

Matsuyama, K., 1992. Agricultural productivity, comparative advantage, and economic growth. Journal of Economic Theory 58, 317-334.

Miller, S.M., Upadhyay, M.P., 2000. The effects of openness, trade orientation, and human capital on total factor productivity. Journal of Development Economics 63, 399-423.

Murphy, K., Shleifer, A., Vishny, R., 1989. Industrialization and the big push. Journal of Political Economy 97 , 1003-1026.

Ng, Y.-K., 2003. Increasing returns and economic efficiency. Mimeo, Monash University.

$\mathrm{Ng}$, Y.-K., Ng, S., 2003. Do the economies of specialization justify the work ethics? An examination of Buchanan's hypothesis. Journal of Economic Behavior and Organization 50, 339-353.

Romer, P., 1987. Growth based on increasing returns due to specialization. American Economic Review Papers and Proceedings 77, 56-62.

Sachs, J., Yang, X., Zhang, D., 2002. Pattern of trade and economic development in the model of monopolistic competition. Review of Development Economics 6, 1-25.

Smith, A., 1776. An Inquiry into the Nature and Causes of the Wealth of Nations. Reprint. University of Chicago Press, Chicago.

Ventura, J., 1997. Growth and interdependence. Quarterly Journal of Economics 112, 57-84.

Wade, R., 1990. Governing the Market: Economic Theory and the Role of Government in East Asian Industrialization. Princeton University Press, Princeton, NJ.

Wood, A., 1994. North-South Trade, Employment and Inequality: Changing Fortunes in A Skill-Driven World. Clarendon Press, Oxford.

Yang, X., Borland, J., 1991. A microeconomic mechanism for economic growth. Journal of Political Economy 99, 460-482.

Yang, X., Ng, Y.-K., 1993. Specialization and Economic Organization: A New Classical Microeconomic Framework. Amsterdam, North-Holland.

Young, A., 1991. Learning by doing and the dynamic effects of international trade. Quarterly Journal of Economics $106,369-406$. 